\title{
Prevalence and Predictive Factors of Induced Abortion among Women in Ghana: Data Analysis of Maternal Health Survey, 2017.
}

\author{
Abdul Rauf Alhassan ${ }^{1 *}$ and John Nyaaba Anyinzaam-Adolipore ${ }^{2}$ \\ ${ }^{1}$ Department of Surgery, Tamale Teaching Hospital, P.O. Box TL 16; Tamale-Ghana. \\ ${ }^{2}$ Department of supervision/inspectorate unit, Ghana education service, P.O. Box KA 20; Karaga-Ghana.
}

*Corresponding Author: Abdul Rauf Alhassan, Department of Surgery, Tamale Teaching Hospital, P.O. Box TL 16; Tamale-Ghana.

Received date: September 29, 2021; Accepted date: October 20, 2021; Published date: November 01,2021

Citation: Abdul R. Alhassan and John N. A. Adolipore. (2021). Prevalence and Predictive Factors of Induced Abortion among Women in Ghana: Data Analysis of Maternal Health Survey, 2017. J Clinical Research and Reports, 9(3); DOI:10.31579/2690-1919/204

Copyright: (C) 2021, Abdul Rauf Alhassan. This is an open access article distributed under the Creative Commons Attribution License, which permits unrestricted use, distribution, and reproduction in any medium, provided the original work is properly cited.

\begin{abstract}
Induced abortion is a common practice for women worldwide; nevertheless, the practice of unsafe abortion rate in Ghana is in height and is a constant issue of public health concern. Objective: The main aim of the study was to identify predictive factors associated with induced abortion among women in Ghana. Methods: Ghana Maternal Health Survey data was used for this study to do an analytic cross-section study. Data analysis was done using SPSS version 20. The association between dependent and independent variables was explored using chi-square and logistic regression. Statistical significance was set at $\mathrm{p}<0.05$. Results: In this study, the prevalence of induced among the respondents was $14.8 \%$, the prevalence was higher $(25.5 \%)$ in Greater Accra Region and lower (3.2\%) in Northern Region. All under-studied independent variables through chi-square analysis were associated with induced abortion with significance. However, in advance analysis through binary logistics regression model predictor factors of induced abortion in Ghana identified were; the age of the respondents', region of orientation, religious affiliation, marital status, ethnicity, exposure to mobile phone and newspaper, and age at first sex. The logistic regression model appropriately explained the outcome variable (induced abortion) since the HosmerLemeshow goodness-of-fit test p-value was more than $0.05\left(\mathrm{X}^{2}(8)=4.428, \mathrm{P}=.817\right)$. Conclusion: The prevalence of abortion in Ghana is still high, hence the need for increase public education on contraceptive use and the adverse effects of abortion through the use of modern media can go a long way to reduce the incidence of induced abortion in Ghana.
\end{abstract}

Running title: Induced abortion in Ghana

Keywords: induced; abortion; prevalence; predictors; women; Ghana

\section{Introduction}

Globally, each year 22 million women are involved in unsafe abortion. Most $(98.0 \%)$ of unsafe abortions happen in developing nations [1]. In 2008, the global rate for unsafe abortion stood at 14 per 1000 women for the age group of 15-44, whereas the rate for Sub- Saharan Africa stood as high as 31 per 1000 women within their reproductive age group of 1544 [1]. Basinga et al., a study that was carried out in Sub- Saharan Africa, did reveal that the majority of induced abortions in the region are largely unsafe as the bulk of them are illegal [2]. In states that are engulfed with poor access to safe abortion services and legal abortions, most women with unplanned pregnancies are alternative to the practice of unsafe abortions [3].

The dangers associated with unsafe abortion range from severe morbidities such as serious bleeding, sepsis, and organ failure to no complications [4-6]. Whereas abortions are becoming less problematic worldwide, this is not the same for Africa as evidence points to a rather high rate of hospitalization resulting from complicated abortion due to unsafe practices from the Eastern and sub-Saharan Africa regions. Globally, Africa has high rates of gynecological hospitalization from unsafe abortion-related complications [7].

The adverse effects of induced abortions are not deterrent factors enough as several studies have shown a substantial percentage of women secure more than one abortion during their reproductive lifetime [8-11]. In Sudan, for example, a study in five hospitals showed that over $40 \%$ of women pursuing medical care for problems of unsafe abortion had a history of at least one earlier unsafe abortion [10]. Also, research in Ethiopia revealed that among women looking for abortion-related services, the incidence of history abortion was $30 \%$ [11].

Induced abortion is a common practice for women worldwide; nevertheless, the practice of unsafe abortion rates in Ghana is in height 
and is a constant issue of public health concern. Abortion increases maternal mortality in Ghana by $15-30 \%$ [12]. The law regarding criminal abortion in Ghana was modified in 1985 making induced abortion legal concerning some situations [13]. However, in Ghana to admittance to harmless abortion practice is hindered by restricted access to legal abortion services, finance, sociocultural barriers, and social stigma [14].

Ghana has endeavored to tackle the problem of unplanned pregnancies leading to unsafe abortions by encouraging the utilization of modern contraceptives, reproductive health strategic plans, and capacity building of trainee midwives in health training institutions to complete abortion care $[12,15]$. Regardless, contraception acceptance remains poor at $25 \%$, and $31 \%$ of pregnancies are unplanned, the incidence of induced abortion has risen to $7 \%$ in 2017 from 5\% in 2007, and illegal abortion is a key issue in maternal morbidity and mortality [12,16,17].

An earlier study by Boah et al. attempted to identify predictors of unsafe abortion in Ghana [18], but their study is different from this current study which attempted to identify predictive factors associated with inducing abortion in Ghana, which involved both safe and unsafe abortion. The findings of this study will be of policy relevance to the Ghanaian Ministry of Health and other foreign experts in the field of female, sexual, and reproductive health.

\section{Materials and Methods}

The study design for this study was an analytic cross-sectional survey using data from the 2017 Ghana Maternal Health Survey (GMHS). The Ghana Statistical Service (GSS) conducted the 2017 GMHS with technical assistance from ICF's Demographic and Health Survey (DHS) program. Ghana's 2010 Population and Housing Census provided the sampling frame (PHC). Eligible participants were women aged 15 to 49 years who were permanent residents of selected households or guests who stayed in selected households the night before the survey. The study's areas and households were selected using a multistage stratified cluster sampling technique. The details of the survey procedures and the questionnaires used can be found in the final report [16].

The study included all the survey participants (25062) and the main dependent variable of the study was the history of ever abortion among the study participants. The independent variables included demographic characteristics, mass media exposure, history of first sexual intercourse, and family planning practice.

\begin{tabular}{|l|l|l|l|}
\hline \multicolumn{2}{|c|}{} & $\begin{array}{l}\text { Frequency } \\
(\mathrm{n}=25062)\end{array}$ & Percentage \\
\hline \multirow{4}{*}{ Age group } & $15-19$ & 4888 & $19.5 \%$ \\
\cline { 2 - 4 } & $20-24$ & 4259 & $17.0 \%$ \\
\cline { 2 - 4 } & $25-29$ & 4179 & $16.7 \%$ \\
\cline { 2 - 4 } & $\geq 30$ & 11736 & $46.8 \%$ \\
\hline \multirow{5}{*}{ Evarital status } & Married & 10869 & $43.4 \%$ \\
\cline { 2 - 4 } & Living with a man & 4183 & $16.7 \%$ \\
\cline { 2 - 4 } & Not in union & 10010 & $39.9 \%$ \\
\hline \multirow{5}{*}{ Ethnicity attended school } & Yes & 18554 & $74.0 \%$ \\
\cline { 2 - 4 } & No & 6508 & $26.0 \%$ \\
\hline \multirow{5}{*}{} & Akan & 8837 & $35.3 \%$ \\
\cline { 2 - 4 } & Ga/Dangme & 1279 & $5.1 \%$ \\
\cline { 2 - 4 } & Ewe & 2474 & $9.9 \%$ \\
\cline { 2 - 4 } & Guan & 905 & $3.6 \%$ \\
\cline { 2 - 4 } & Mole-dagbani & 7651 & $30.5 \%$ \\
\cline { 2 - 4 } & Grusi & 1284 & $5.1 \%$ \\
\cline { 2 - 3 } & Gurma & 1799 & $7.2 \%$ \\
\cline { 2 - 3 } & Mande & 293 & $1.2 \%$ \\
\cline { 2 - 3 } & Other & 540 & $2.2 \%$ \\
\hline
\end{tabular}

\section{Statistical Analysis}

Statistical analysis was done using SPSS Statistics for Windows, Version 20.0 (IBM SPSS Statistics for Windows, Version 20.0. Armonk, NY: IBM Corp). Categorical variables results were presented using frequencies and percentages using tables and figures. Continuous variables were results were represented using mean and standard deviation. The association between dependent and independent variables was done using chi-square. Factors with a significant association at the bivariate level were further modeled using a binary logistics regression model to identify predictor variables of induced abortion. Statistical significance was set at a p-value of $<0.05$.

\section{Ethical consideration}

The ICF Institutional Review Board (IRB) approved the protocol for the 2017 GMHS. Meanwhile, ethical approval was not necessary for this study because it involved a secondary analysis of a dataset without exposure to the identity of the respondents and their households. Nonetheless, permission was obtained from ICF through the DHS program for the use of the datasets in this study and the terms of data use were observed.

\section{Results}

\section{Demographic characteristics of the respondents'}

There were 25062 respondents (women aged from 15 to 49 years) in this survey, the average age of the women was $29.5 \pm 9.8$, with a modal age of 15 . The majority $(74.0 \%)$ of the respondents were educated with at least primary level education. In terms of ethnicity, the majority (35.3\%) were Akans, and then $30.5 \%$ for Mole-Dagbani. At the time of the survey, the majority of the respondents were married $(43.4 \%)$. The religion that dominated the respondents was Christianity $(70.8 \%)$ than Islam $(24.3 \%)$ and residency was almost the same for Urban and Rural, 50.1\%, and $49.9 \%$ respectively. The study was across the than ten regions of Ghana, $31.7 \%$ for coastal belt (Western $(9.3 \%)$, Central (6.4\%), Greater $(10.1 \%)$ and Volta $(5.8 \%)$ ), 30.4\% for the forest belt (Eastern (8.7\%), Ashanti $(12.5 \%)$ and Brong-Ahafo (9.2\%)) and $38.0 \%$ for the savanna belt (Northern (16.8\%), Upper West (10.8\%) and Upper East (10.4\%)) (Table $1)$. 


\begin{tabular}{|l|l|l|l|}
\hline \multirow{4}{*}{ Religion } & Christianity & 17751 & $70.8 \%$ \\
\cline { 2 - 4 } & Islam & 6080 & $24.3 \%$ \\
\cline { 2 - 4 } & Traditional & 617 & $2.5 \%$ \\
\cline { 2 - 4 } & Other religion & 3 & $0.0 \%$ \\
\cline { 2 - 4 } & No religion & 611 & $2.4 \%$ \\
\hline \multirow{3}{*}{ Type of place of residence } & Urban & 12544 & $50.1 \%$ \\
\cline { 2 - 4 } & Rural & 12518 & $49.9 \%$ \\
\hline & Coastal belt & 7938 & $31.7 \%$ \\
\cline { 2 - 4 } & Forest belt & 7610 & $30.4 \%$ \\
\cline { 2 - 3 } & Savanna belt & 9514 & $38.0 \%$ \\
\hline
\end{tabular}

Table 1: Demographic characteristics of the respondents'

\section{Other independent variables}

For those who responded to these questions majority $(69.2 \%)$ of the respondents were not into reading newspapers. Meanwhile, the majority of them listen to the radio and watch television at least once a week
(46.0\% and $52.1 \%$ respectively). With ownership mobile, the majority $(64.3 \%)$ were having a mobile phone and about $62.7 \%$ of the respondents were having used the internet almost every day. Moreover, $81.6 \%$ of them knew their fertile period and about $76.3 \%$ of them had their first sex at 15 -19 years (Table 2).

\begin{tabular}{|l|l|l|l|}
\hline \multicolumn{2}{|c|}{} & Frequency & Percentage \\
\hline \multirow{2}{*}{ Reads new paper } & Yes & 3805 & $30.8 \%$ \\
\cline { 2 - 4 } & No & 8534 & $69.2 \%$ \\
\hline \multirow{2}{*}{ Listens to radio } & Yes & 17830 & $71.1 \%$ \\
\cline { 2 - 4 } & No & 7232 & $28.9 \%$ \\
\hline \multirow{2}{*}{ watches TV } & Yes & 17783 & $71.0 \%$ \\
\cline { 2 - 4 } & No & 7279 & $29.0 \%$ \\
\hline \multirow{3}{*}{ Ever used internet } & Yes & 16117 & $64.3 \%$ \\
\cline { 2 - 4 } Age of first sex & No & 8945 & $35.7 \%$ \\
\hline \multirow{5}{*}{ Knowledge of fertility period } & Yes & 5215 & $20.8 \%$ \\
\cline { 2 - 4 } & No & 19847 & $79.2 \%$ \\
\hline & $7-14$ & 0 & $0.0 \%$ \\
\cline { 2 - 4 } & $15-19$ & 14281 & $76.3 \%$ \\
\cline { 2 - 4 } & $20-24$ & 3897 & $20.8 \%$ \\
\cline { 2 - 4 } & $25-29$ & 481 & $2.6 \%$ \\
\cline { 2 - 4 } & $\geq 30$ years & 63 & $0.3 \%$ \\
\hline
\end{tabular}

Table 2: Other independent variables

\section{Induced abortion in Ghana}

The prevalence of induced abortion among the respondents was $14.8 \%$. According to the respondents,' the major reasons for abortion included: lack of readiness to be a mother (13.9\%), lack of money to care for the baby $(13.3 \%)$, to be able to continue schooling (11.7\%), of space childbirth $(11.1 \%)$ and partner denial of pregnancy $(9.0 \%)$.

\section{Regional proportions of induced abortion}

Proportionally, the region with the highest number of respondents with abortion history was Greater Accra Region (25.5\%), followed by Ashanti Region (23.8\%), then Western Region (20.7\%), and Brong Ahafo Region $(20.4 \%)$. And the region with lowest proportion of abortion history was 
Northern Region $(3.2 \%), X^{2}(9,25062)=1530.280, \mathrm{P} \leq 0.001$ (Figure 1).

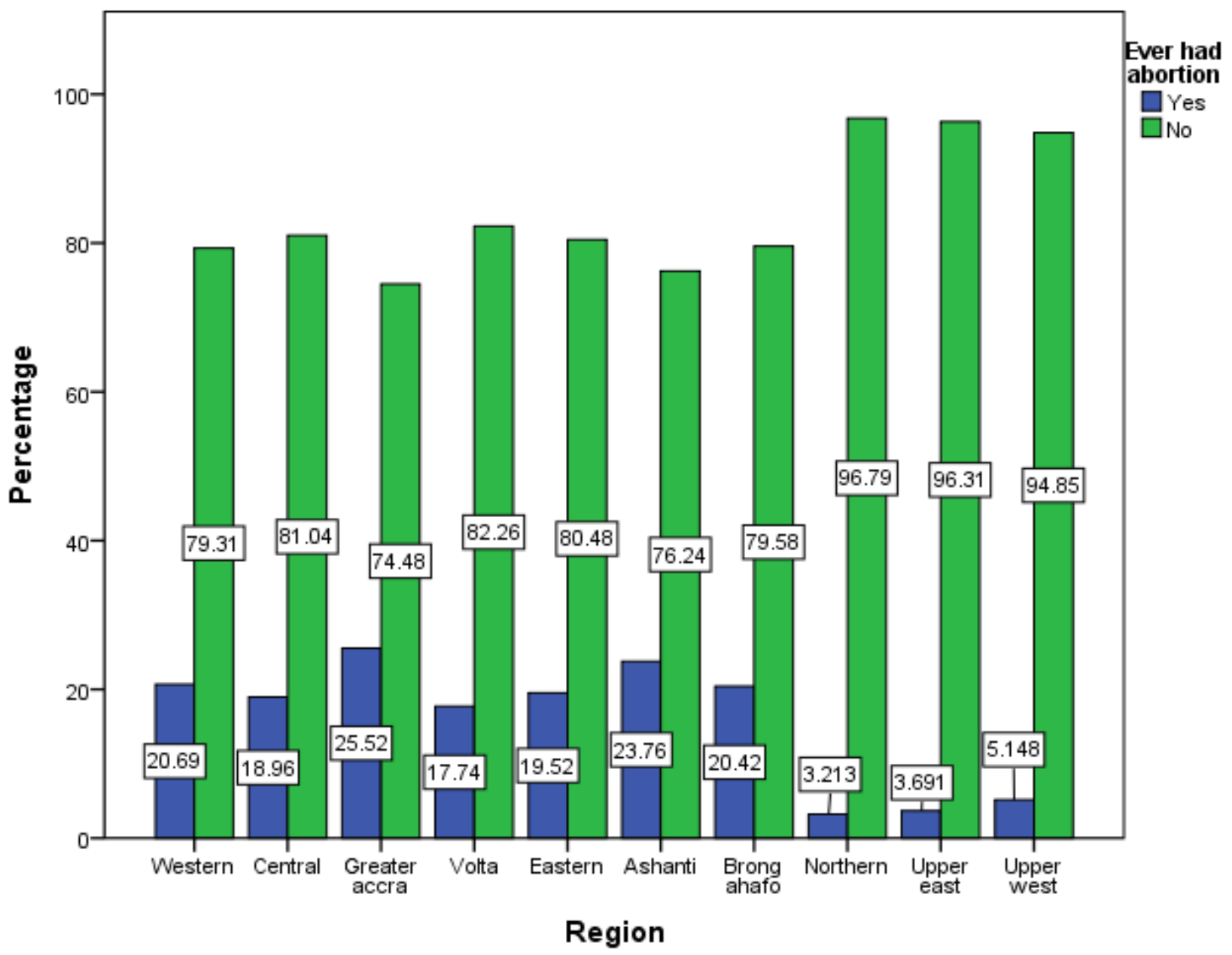

Figure 1: Proportion of abortion history across regions of Ghana

\section{Factors associated with induces abortion in Ghana}

With chi-square analysis, all demographic characteristics of the respondents' indicated a significant relation with respondents' history of abortion. Age group $X^{2}(6,25062)=853.48, \mathrm{P} \leq 0.001$, marital status $X^{2}(2$,
$25062)=571.465, \mathrm{P} \leq 0.001$, ever attended school $X^{2}(1,25062)=$ $415.993, \mathrm{P} \leq 0.001$, religion $X^{2}(3,25062)=661.257, \mathrm{P} \leq 0.001$, ethnicity $X^{2}(8,25062)=1583.835, \mathrm{P} \leq 0.001$ and type of place of residence $X^{2}(1$, $25062)=453.478, \mathrm{P} \leq 0.001$ (Table 3 ).

\begin{tabular}{|c|c|c|c|c|c|c|}
\hline & & \multicolumn{2}{|c|}{ Ever had abortion } & \multirow[b]{2}{*}{$X^{2}$} & \multirow[b]{2}{*}{ df } & \multirow[b]{2}{*}{ P-value } \\
\hline & & Yes & $\mathrm{No}$ & & & \\
\hline \multirow{4}{*}{ Age group } & $15-19$ & 129 & 4759 & 850.863 & 3 & .000 \\
\hline & $20-24$ & 514 & 3745 & & & \\
\hline & $25-29$ & 762 & 3417 & & & \\
\hline & $\geq 30$ & 2297 & 9439 & & & \\
\hline \multirow{3}{*}{ Marital status } & Married & 1420 & 9449 & 571.465 & 2 & .000 \\
\hline & Co-habitation & 1115 & 3068 & & & \\
\hline & Single & 1167 & 8843 & & & \\
\hline \multirow{2}{*}{$\begin{array}{ll}\begin{array}{l}\text { Ever } \\
\text { school }\end{array} & \text { attended } \\
\end{array}$} & Yes & 3243 & 15311 & 415.993 & 1 & .000 \\
\hline & No & 459 & 6049 & & & \\
\hline \multirow{4}{*}{ Religion } & Christianity & 3271 & 14480 & 661.257 & 3 & .000 \\
\hline & Islam & 342 & 5738 & & & \\
\hline & Traditional & 22 & 595 & & & \\
\hline & No religion & 67 & 547 & & & \\
\hline \multirow{4}{*}{ Ethnicity } & Akan & 2150 & 6687 & 1583.835 & 8 & .000 \\
\hline & $\mathrm{Ga} /$ Dangme & 294 & 985 & & & \\
\hline & Ewe & 499 & 1975 & & & \\
\hline & Guan & 135 & 770 & & & \\
\hline
\end{tabular}




\begin{tabular}{|l|l|l|l|l|l|l|}
\cline { 2 - 7 } & Mole-Dagbani & 384 & 7267 & & & \\
\cline { 2 - 7 } & Grusi & 76 & 1208 & & & \\
\cline { 2 - 7 } & Gurma & 91 & 1708 & & & \\
\cline { 2 - 7 } & Mande & 27 & 266 & & & .000 \\
\cline { 2 - 7 } & Other & 46 & 494 & & & \\
\hline \multirow{2}{*}{$\begin{array}{l}\text { Type of place of } \\
\text { residence }\end{array}$} & Urban & 2451 & 10093 & 453.478 & 1 & \\
\cline { 2 - 7 } & Rural & 1251 & 11267 & & & \\
\hline
\end{tabular}

Chi-square analysis revealed a significant relationship between the other independent variables and induced abortion. Reads newspaper $X^{2}(1,25062)$ $=3.979, \mathrm{P} \leq 0.046$, listen to radio $X^{2}(1,25062)=287.137, \mathrm{P} \leq 0.001$, watches $\mathrm{TV} X^{2}(1,25062)=435.607, \mathrm{P} \leq 0.001$, own mobile phone $X^{2}(1,25062)$ $=785.655, \mathrm{P} \leq 0.001$, ever used internet $X^{2}(1,25062)=71.401, \mathrm{P} \leq 0.001$, age at first sex $X^{2}(3,25062)=128.974, \mathrm{P} \leq 0.001$, knowledge of fertile period $X^{2}(1,25062)=221.923, \mathrm{P} \leq 0.001$ (Table 4$)$.

\begin{tabular}{|c|c|c|c|c|c|c|}
\hline & \multicolumn{2}{|c|}{ Ever had abortion } & \multirow[b]{2}{*}{$X^{2}$} & \multirow[b]{2}{*}{ df } & \multirow[b]{2}{*}{ p-value } \\
\hline & & Yes & $\mathrm{No}$ & & & \\
\hline \multirow{2}{*}{ Reads new paper } & Yes & 564 & 3241 & 3.979 & 1 & .046 \\
\hline & No & 1386 & 7148 & & & \\
\hline \multirow{2}{*}{ Listens to radio } & Yes & 3065 & 14765 & 287.137 & 1 & .000 \\
\hline & No & 637 & 6595 & & & \\
\hline \multirow{2}{*}{ watches TV } & Yes & 3159 & 14624 & 435.607 & 1 & .000 \\
\hline & No & 543 & 6736 & & & \\
\hline \multirow{2}{*}{ Own a mobile phone } & Yes & 3135 & 12982 & 785.655 & 1 & .000 \\
\hline & $\mathrm{No}$ & 567 & 8378 & & & \\
\hline \multirow{2}{*}{ Ever used internet } & Yes & 963 & 4252 & 71.401 & 1 & .000 \\
\hline & $\mathrm{No}$ & 2739 & 17108 & & & \\
\hline \multirow{5}{*}{ Age at first sex } & $7-14$ & 0 & 0 & 128.974 & 3 & .000 \\
\hline & $15-19$ & 2593 & 11688 & & & \\
\hline & $20-24$ & 465 & 3432 & & & \\
\hline & $25-29$ & 31 & 450 & & & \\
\hline & $\geq 30$ & 3 & 60 & & & \\
\hline \multirow{2}{*}{$\begin{array}{l}\text { Knowledge of fertile } \\
\text { period }\end{array}$} & Yes & 3345 & 17105 & 221.923 & 1 & .000 \\
\hline & No & 357 & 4255 & & & \\
\hline
\end{tabular}

Table 4: Chi-square analysis of respondents' other independent variables and their history of induce abortion

\section{Predictors of induced abortion}

In this current study woman practice of induced abortion was more likely as her age advanced, $20-24$ years $(\mathrm{AOR}=3.27,95 \%$, C.I. $=2.37-4.52)$, $25-29$ years $(\mathrm{AOR}=6.23,95 \%$, C.I. $=4.50-8.63)$ and $\geq 30(\mathrm{AOR}=$ $9.74,95 \%$, C.I. $=7.06-13.43$ ). Women in marriage were more protected from induced abortion, co-habitation $(\mathrm{AOR}=1.73,95 \%$, C.I. $=1.47-$ $2.03)$, and single $(\mathrm{AOR}=1.19,95 \%$, C.I. $=1.03-1.38)$. Women apart from being Christians were protected from induced abortion, Islam (AOR $=0.71,95 \%$, C.I. $=0.55-0.92)$, traditional $(\mathrm{AOR}=0.11,95 \%$, C.I. $=$ $0.02-0.86)$ and no religion $(\mathrm{AOR}=0.45,95 \%$, C.I. $=0.22-0.95)$. In terms of regional prediction, two regions when compared to Western region predicted induce abortion, Ashanti $(\mathrm{AOR}=1.29,95 \%$, C.I. $=1.04$ -1.59) and Brong-Ahafo (AOR = 1.39, C.I. = 1.09 - 1.77). Meanwhile, women from the three northern regions were less likely to practice induced abortion as compare to those from Western region, Northern $(\mathrm{AOR}=0.41,95 \%$, C.I. $=0.28-0.59)$, Upper East $(\mathrm{AOR}=0.42,95 \%$, C.I. $=0.27-0.64)$ and Upper west $(\mathrm{AOR}=0.64,95 \%$, C.I. $=0.43-0.95)$. And with ethnicity, women of Mole-Dagbani tribe were less likely 0.6 times to practice induced abortion when compared to those from Akan tribe. With the use of modern media, those without exposure to mobile phone use were less likely to practice induce abortion (AOR $=0.79,95 \%$, C.I. $=0.64-0.98)$. However, induced abortion was more likely among those without exposure to newspaper $(\mathrm{AOR}=1.15,95 \%$, C.I. $=1.01-$ 1.31). Finally, woman age of first sex was associated with induced abortion, women with first sex after 19 years were protected from induced abortion, $20-24$ years $(\mathrm{AOR}=0.37,95 \%$, C.I. $=0.32-0.43), 25-29$ years $(\mathrm{AOR}=0.11,95 \%$, C.I. $=0.07-0.17)$ and $\geq 30$ years $(\mathrm{AOR}=0.04,95 \%$, C.I. $=0.01-0.27)($ Table 5).

\begin{tabular}{|c|c|c|c|c|c|c|}
\hline \multirow[b]{2}{*}{ Variables in the equation } & \multirow[b]{2}{*}{$\mathrm{B}$} & \multirow[b]{2}{*}{ Wald } & \multirow[b]{2}{*}{ P-value } & \multirow[b]{2}{*}{ AOR } & \multicolumn{2}{|c|}{$95 \%$ C.I. for AOR } \\
\hline & & & & & Lower & Upper \\
\hline $15-19$ & & Reference & .000 & 1 & & \\
\hline $20-24$ & 1.186 & 51.910 & .000 & 3.274 & 2.371 & 4.521 \\
\hline $25-29$ & 1.830 & 121.514 & .000 & 6.232 & 4.502 & 8.629 \\
\hline$\geq 30$ & 2.276 & 191.936 & .000 & 9.736 & 7.056 & 13.434 \\
\hline Married & & Reference & .000 & 1 & & \\
\hline Co-habitation & .548 & 45.193 & .000 & 1.729 & 1.474 & 2.028 \\
\hline Single & .173 & 5.332 & .021 & 1.189 & 1.027 & 1.378 \\
\hline Ever attended (Yes) & & Reference & & & & \\
\hline Ever attended (No) & -.175 & .168 & .682 & .839 & .363 & 1.940 \\
\hline Christianity & & Reference & .002 & 1 & & \\
\hline Islam & -.341 & 6.908 & .009 & .711 & .552 & .917 \\
\hline Traditional & -2.169 & 4.431 & .035 & .114 & .015 & .861 \\
\hline
\end{tabular}




\begin{tabular}{|c|c|c|c|c|c|c|}
\hline No religion & \begin{tabular}{|l|l|} 
\\
\end{tabular} & 4.384 & .036 & .452 & .215 & .950 \\
\hline Akan & & Reference & .005 & 1 & & \\
\hline Ga/Dangme & -.090 & .603 & \begin{tabular}{|l|l|}
.438 \\
\end{tabular} & \begin{tabular}{|l|l}
.914 \\
\end{tabular} & .727 & 1.148 \\
\hline Ewe & -.126 & 1.382 & .240 & .882 & .715 & 1.088 \\
\hline Guan & -.212 & 1.607 & .205 & .809 & .583 & 1.123 \\
\hline Mole-Dagbani & -.587 & 16.209 & \begin{tabular}{|l|}
.000 \\
\end{tabular} & .556 & .418 & \begin{tabular}{|l|l|}
.740 \\
\end{tabular} \\
\hline Grusi & -.270 & 1.502 & .220 & .763 & .495 & 1.176 \\
\hline Gurma & -.027 & .017 & \begin{tabular}{|l|l|}
.897 \\
\end{tabular} & .973 & .644 & 1.471 \\
\hline Mande & .312 & .517 & \begin{tabular}{|l|l|}
.472 \\
\end{tabular} & 1.366 & .584 & 3.196 \\
\hline Other & $\mid-.526$ & 3.537 & .060 & .591 & .341 & 1.022 \\
\hline Residence (Urban) & & Reference & & & & \\
\hline Residence (Rural) & \begin{tabular}{|l|l|} 
\\
\end{tabular} & 1.068 & .301 & .929 & .807 & 1.068 \\
\hline Western & & \begin{tabular}{|l|} 
Reference \\
\end{tabular} & .000 & 1 & & \\
\hline Central & -.254 & 3.694 & .055 & .776 & .599 & 1.005 \\
\hline Greater Accra & .207 & 3.377 & .066 & 1.230 & .986 & 1.535 \\
\hline Volta & -.111 & .485 & .486 & .895 & .654 & 1.224 \\
\hline Eastern & -.167 & 2.071 & .150 & .846 & .674 & 1.062 \\
\hline Ashanti & .253 & 5.416 & \begin{tabular}{|l|l|}
.020 \\
\end{tabular} & 1.287 & 1.041 & 1.593 \\
\hline Brong-Ahafo & .328 & 6.939 & .008 & 1.388 & 1.088 & 1.772 \\
\hline Northern & -.905 & 22.279 & .000 & .405 & .278 & .589 \\
\hline Upper East & -.875 & 16.291 & \begin{tabular}{|l|l|}
.000 \\
\end{tabular} & \begin{tabular}{|l|l|}
.417 \\
\end{tabular} & .272 & \begin{tabular}{|l|l|}
.637 & \\
\end{tabular} \\
\hline Upper west & -.453 & 4.934 & .026 & .636 & .426 & .948 \\
\hline Newspaper use (Yes) & & Reference & & & & \\
\hline Newspaper use (No) & .137 & 4.149 & .042 & 1.147 & 1.005 & 1.308 \\
\hline Radio use (Yes) & & Reference & & & & \\
\hline Radio use (No) & -.052 & .351 & .554 & .949 & .798 & 1.128 \\
\hline TV use (Yes) & & Reference & & & & \\
\hline TV use (No) & -.199 & 3.497 & .061 & .820 & .666 & 1.010 \\
\hline Mobile Phone (Yes) & & Reference & & & & \\
\hline Mobile Phone (No) & -.231 & 4.574 & .032 & .794 & .642 & .981 \\
\hline Internet use (Yes) & & Reference & & & & \\
\hline Internet use (No) & -.127 & 3.536 & .060 & .881 & .772 & 1.005 \\
\hline First sex (15 -19) & & Reference & .000 & 1 & & \\
\hline First sex (20-24) & -.984 & 176.059 & .000 & .374 & .323 & .432 \\
\hline First sex (25-29) & -2.247 & 90.221 & .000 & .106 & .067 & .168 \\
\hline First sex $(\geq 30)$ & -3.313 & 10.663 & .001 & .036 & .005 & .266 \\
\hline Know of the fertile period (Yes) & & Reference & & & & \\
\hline Know of the fertile period (No) & -.179 & 2.319 & .128 & .836 & .664 & 1.053 \\
\hline
\end{tabular}

Dependent variable (ever had abortion) dummy code as $0=$ No and $1=$ Yes. H-L GOF test $X^{2}(8)=4.428, \mathrm{P}=.817$

Table 5: Binary logistics regression for predictors of induced abortion in Ghana

The logistic regression model appropriately explained the outcome variable (induced abortion) since the Hosmer-Lemeshow goodness-of-fit test $p$ - value was more than $0.05\left(X^{2}(8)=4.428, \mathrm{P}=.817\right)$.

\section{Discussion}

The main purpose of this study was to find factors associated with induced abortion in Ghana among women. According to the Guttmacher Institute, 23\% of all pregnancies in Ghana for the year 2017 ended in abortion [19]. In this study, the prevalence of induced abortion history (ever had an abortion) among the respondents was $14.8 \%$. This study finding is a little higher than a similar study, which reported cases of induced abortions to be $13.6 \%$ in rural Ghana [20]. However, this was lower than another national prevalence $(21.1 \%)$ in Nepal [21]. And the major reasons for induced abortion among others were, lack of readiness to be a mother, and lack of money to care for the baby. This is in line with earlier studies which also reported that in most nations, the most commonly named reasons for induced abortion were socioeconomic difficulties and unplanned pregnancies [22, 23].
In a study by Guttmacher Institute, more than half (53\%) of all pregnancies in Ghana were unintentional, stretching from $23 \%$ in the Northern zone to $51 \%$ in the Coastal zone and $66 \%$ in the Middle Zone and this resulted in abortions from 24 for the Northern zone to 51 to the Middle Zone and 45 for the Coastal zone per 1000 women [19]. In this present study, proportionally the region with the highest number of respondents with induced abortion history was in the coastal zone and the lowest in the northern zone. This confirms the regional prediction, two regions when compared to the Western region predicted induced abortion. Women from the Ashanti and Brong-Ahafo regions were more likely to practice induced abortion in Ghana. Meanwhile, women from the three northern regions were less likely to practice induced abortion as compared to those from the Western region. This further confirms why women of the Mole-Dagbani tribe were less likely 0.6 times to practice induced abortion when compared to those from the Akan tribe. Similar to a national study ethnicity and region of the women predicted abortion [21]. 
In this current study, a woman's practice of induced abortion was more likely as her age advance. This study result is the same when compared to an earlier study in Nepal [21]. However, this is not familiar to earlier studies in Africa, which all reported higher age was a protective factor against abortion induction [20,23]. The explanation is that younger women are more predisposed to sexual coercion and rape which can lead to unintended pregnancies and a good number of induced abortions are consequences due to unintended pregnancies [23-25].

Also, married women were less likely to practice induce abortion as compared to single women and women in the co-habitation union. This study finding is similar to studies in Ghana, which reported that unmarried women were more likely to induce abortion as compared to married women [20,26]. However, a similar study in Ethiopia reported no significant association between induced abortion and marital status [23].

Moreover, exposure to modern mass media such as newspapers was a protective factor against inducing abortion in Ghana, but those exposed to a mobile phone were more likely to practice induce abortion in Ghana. This finding supports the conclusion that exposure to the media may be enough to change one's sexual and reproductive behavior if the contents of the particular media source do positively address sexual and reproductive health issues [27].

Finally, a woman's age of first sex was associated with induced abortion; women with first sex after 19 years were less likely to practice induce abortion. According to Magnusson et al., age at first intercourse is connected with inconsistent or nonuse of contraceptives in later life [28].

This study is not without limitations, the study did not explore all factors known to be associated with induced abortion. Furthermore, the data used for this study was a cross-sectional study that has to do with the recall of information from the past, and recall bias was more likely, especially with regards to questions on abortion.

\section{Conclusion}

The main purpose of the study was to identify factors associated with abortion in Ghana. The following factors were identified to be a predictor of induced abortion in Ghana: age of the woman, marital status, media exposure, age at first sex, ethnicity, and region of the woman. It is recommended that increase public education on contraceptive use and the adverse effects of abortion through the use of modern media can go a long way to reduce the incidence of induced abortion in Ghana.

\section{Data Availability}

All dataset related to the findings of this study is available online at www.dhsprogram.com.

\section{Conflicts of Interest}

There is no conflict of interest with this submission.

\section{Funding Statement}

Funding for this study was completed by authors without any external funding.

\section{References}

1. World Health Organization (WHO). (2011). Unsafe Abortion: Global and Regional Estimates of the Incidence of Unsafe Abortion and Associated Mortality in 2008, Sixth edn. Geneva

2. Basinga P, Moore A, Singh S, Carlin E, Birungi F, Ngabo F. (2012). Abortion incidence and postabortion care in Rwanda. Stud Fam Plann.11-20.
3. Sedgh G, Henshaw S, Singh S, Ahman E, Shah I. (2007). Induced abortion: estimated rates and trends worldwide. Lancet. 370(9595): 1338-1345.

4. Ganatra B, Tuncalp O, Johnston H, Johnson JB, AM G, Temmerman M. (2014). From concept to measurement: operationalizing WHO's definition of unsafe abortion. Bull World Health Organ. World Health Organisation. 155.

5. Haddad L, Nour N. (2009). Unsafe abortion: unnecessary maternal mortality. Rev. Obstet Gynecol. 2(2): 122-126.

6. Grime D, Benson J, Singh S, Romero M, Ganatra B, Okonofua F, et al. (2006). Unsafe abortion: the preventable pandemic. The Lancet. 368(9550): 1908-1919.

7. Singh S. (2006). Hospital admissions resulting from unsafe abortion: estimates from 13 developing countries. Lancet. 368(9550): 1887-1892.

8. Thapa S, Neupane S. (2013). Risk factors for repeat abortion in Nepal. Int J Gynecol Obstet. 120(1): 32-6.

9. Stone N, Ingham R. (2011). Who presents more than once? Repeat abortion among women in Britain. Fam Plann Reprod Health Care. 37(4):209-215.

10. Kinaro J, Ali T, Schlangen, Mack J. (2009). Unsafe abortion and abortion care in Khartoum, Sudan. Reprod Health Matters. 17(34):71-77.

11. Prata N, Holston M, Fraser A, Melkamu Ya. (2013). Contraceptive use among women seeking repeat abortion in Addis Ababa, Ethiopia. Afr J Reprod Health. 2017(4): 56-65.

12. Rominski SD, Lori JR. (2014). Abortion care in Ghana: a critical review of the literature. African Journal of Reproductive Health. 18(3): 17-35.

13. Ahiadeke C. (2001). Incidence of Induced Abortion in Southern Ghana. International Family Planning Perspectives. 27(2): 96101.

14. Payne CM, Debbink MP, Steele EA, et al. (2013). Why women are dying from unsafe abortion: narratives of Ghanaian abortion providers. African Journal of Reproductive Health. 118-128.

15. Sundaram A, Juarez F, Ahiadeke C, Bankole A, Blades N. (2015). The impact of Ghana's R3M programme on the provision of safe abortions and postabortion care. Health Policy and planning. 30(8): 1017-1031.

16. Ghana Statistical Service, Ghana Health Service and ICF. Ghana Maternal Health Survey 2017. Accra, Ghana: 2018.

17. Ghana Statistical Service GHSaII. Ghana Demographic and Health Survey, 2014. Rockville, Maryland, USA: 2015.

18. Boah M, Bordotsiah S, Kuurdong S. (2018). Predictors of Unsafe Induced Abortion among Women in Ghana. Hindawi Journal of Pregnancy.1-8.

19. Guttmacher Institute. (2020). Incidence of Abortion and Provision of Abortion-Related Services in Ghana. Guttmacher Institute.

20. Adjei G, Enuameh Y, Asante KP, Baiden F, Nettey OEA, Abubakari S, et al. (2015). Predictors of abortions in Rural Ghana: a cross-sectional study. BMC Public Health. 15(202): 1-7.

21. Yogi A, Prakash K, Neupane S. (2018). Prevalence and factors associated with abortion and unsafe abortion in Nepal: a nationwide cross-sectional study. BMC Pregnancy and Childbirth.1-10.

22. Chae S, Desai S, Crowell M, Sedgh G. (2017). Reasons why women have induced abortions: a synthesis of findings from 14 countries. HHS Public Access.1-18.

23. Tesfaye G, Hambisa MT, Semahegn A. (2014). Induced Abortion and Associated Factors in Health Facilities of Guraghe Zone, Southern Ethiopia. Journal of Pregnancy. 1-8.

24. Glasier A, Gulmezoglu AM, Schmid GP, Moreno CG, Van Look PF. (2006). Sexual and reproductive health: a matter of life and death. The Lancet. 368(9547): 1595-1607. 
25. Olukoya AA, Kaya A, Ferguson BJ, AbouZahr C. (2001). Unsafe abortion in adolescents. International Journal of Gynecology. 75(2): 137-147.

26. Klutsey EE, Ankomah A. (2014). Factors associated with induced abortion at selected hospitals in the Volta Region, Ghana. International Journal of Women's Health. 809-815.
27. Kwankye SO, August E. (2007). Media Exposure and Reproductive Health Behaviour among Young Females in Ghana. African Population Studies. 79-108.

28. 28. Magnusson BM, Masho SW, Lapane KL. (2012). Early Age at First Intercourse and Subsequent Gaps in Contraceptive. Journal of Women's Health.73-79.
This work is licensed under Creative Commons Attribution 4.0 License

\section{To Submit Your Article Click Here: Submit Manuscript}

DOI: $10.31579 / 2690-1919 / 204$
Ready to submit your research? Choose Auctores and benefit from:

$>$ fast, convenient online submission

$>$ rigorous peer review by experienced research in your field

$>$ rapid publication on acceptance

$>$ authors retain copyrights

$>$ unique DOI for all articles

> immediate, unrestricted online access

At Auctores, research is always in progress.

Learn more auctoresonline.org/journals/journal-of-clinical-research-andreports 